\title{
Phenylketonuria: a review
}

\author{
J. S. Y'U \\ M.B., M.R.A.C.P., D.C.H. \\ Department of Child Health, University of Sydney, \\ Royal Alexandra Hospital for Children, Camperdown, N.S.W. 2050
}

\section{Summary}

The development of a practical screening procedure for phenylketonuria and the improvement in methods of chemical analysis have led to a realization that Folling's (1934) disease of phenylketonuria is not a single entity.

In this commentary, the current view on some aspects of phenylketonuria will be reviewed and the problems illustrated by experience gained in the Phenylketonuria Clinic at the Royal Alexandra Hospital for Children in Sydney, at present attended by fifty-six children. From April 1964, fifty-six infants and children were referred because of a positive screening test. Six were no longer abnormal at the time of retesting, forty-two had classical phenylketonuria and eight showed an atypical pattern. Subsequent family studies revealed five other classical phenylketonuric children, all of whom were retarded, and one other atypical phenylketonuric boy.

Screening surveys and the establishment of a chemical diagnosis

It is widely held that a low phenylalanine diet is responsible for the encouraging results in infants with phenylketonuria treated early (Hsia, 1967; Fuller, 1967; Kennedy et al., 1967) and that this improvement is not solely due to the inclusion of infants who would otherwise have shown good intellectual attainments without restrictions, as Bessman has suggested (1966). If we accept the efficacy of treatment then it is important to make the diagnosis and to start dietary treatment as early as possible. There is no evidence that the lowering of serum phenylalanine levels influences any existing neurological damage or intellectual deficit (Woolf et al., 1958), though aspects of behaviour may be modified. If the diagnosis of phenylketonuria is to be made before the onset of signs and symptoms, all newborn infants must be routinely screened.

The present state of screening procedures has been well reviewed by Woolf (1968). Screening procedures available are listed in Table 1 . Methods using wet urine samples have proven overwhelmingly difficult in the collection of the specimen (Gibbs \& Woolf, 1959). The use of a proprietary ferric chloride buffered test strip ('Phenistix') whilst avoiding some of

TABLE 1. Screening procedures for phenylketonuria detection

1. Urine testing

(a) Colorimetric methods for phenylpyruvic acid (Ferric chloride).

(b) Chromatographic methods for aminoacids.

2. Blood samples on filter paper

(a) Bacterial inhibition test (Guthrie Test).

(b) Chemical analysis: spectrophotometric or fluorometric.

these problems, is unsatisfactory and may miss phenylketonuria in its early stages (Armstrong et al., 1961) and atypical cases with mildly elevated serum phenylalanine levels. Filter paper urine examined by chromatographic methods is useful and is widely employed (Woolf, 1967; Turner \& Brown, 1967).

Capillary blood samples collected on filter paper and dried will detect even mild cases of hyperphenylalaninaemia. The specimens are generally assayed by a microbiological inhibition technique (Guthrie $\&$ Susi, 1963), but more recently fluorometric methods have been used (Searle et al., 1967).

The methods using blood samples are the most reliable form of case finding currently available. If they are done from the fifth day of life onwards, they will detect minor degrees of hyperphenylalaninaemia as seen in the very young phenylketonuric infant and in atypical cases. In those countries where hospital deliveries form the major source of births, surveys using filter paper blood provide the simplest means of ensuring a high rate of cover. In New South Wales, the Guthrie test is performed free by the State Health Authority, but the 
survey depends on the co-operation of individual hospitals and mothers. One reason for missing phenylketonuric infants has been the overzealous hospital where the Guthrie test sample has been collected at 2-3 days of age, before an adequate dietary intake has enabled the blood level of phenylalanine to rise to an abnormal height.

In New South Wales, a double screening survey procedure is used (Turner \& Brown, 1967). Guthrie tests are performed at 6-10 days, before discharge from maternity hospitals. Then when the infant is brought to a Baby Health Centre for mothercraft supervision and assistance at 2-6 weeks, filter paper is given to the mother and, after this has been saturated with urine, it is dried and returned by the mother to a central laboratory. The paper is examined by one-way chromatography for urinary aminoacids. This double method would seem the best screening procedure currently available and has the added advantages of detecting other disorders with abnormal urinary metabolites.

\section{Hyperphenylalaninaemia}

Guthrie testing has revealed a large pool of infants with moderately elevated serum phenylalanine levels, many of whom do not progress to a classical phenylketonuria pattern. A lot of confusion has arisen from the lack of strict definition of the nomenclature used.

Most cases of hyperphenylalaninaemia can be grouped into one of five groups (Table 2).

TABLE 2. Hyperphenylalaninaemia

1. Classical phenylketonuria.

2. Phenylketonuria with abnormalities of phenylalanine transaminase.

3. Transient neonatal hyperphenylalaninaemia.

4. Atypical phenylketonuria.

5. Maternal phenylketonuria.

\section{(i) Classical phenylketonuria}

In classical phenylketonuria the fasting serum phenylalanine level, in infants over 6-10 days, is 20 $\mathrm{mg}$ per $100 \mathrm{ml}$ or higher provided the dietary intake of mild is sufficient. By 4 weeks the level is frequently in excess of $30 \mathrm{mg}$ per $100 \mathrm{ml}$. Abnormal amounts of phenylalanine, phenylpyruvic acid and ortho-hydroxyphenylacetic acid are present in the urine from the second week onwards. These babies show a marked intolerance to an oral phenylalanine load with a poor rise in tyrosine. In the early neonatal period the importance of an adequate protein intake at the time of testing is important. This is illustrated by the following case history:

Infant A. McG. (RAHC: 175794) was admitted at 14 days of age for investigation of projectile vomiting. Pyloric stenosis was diagnosed. After rehydra- tion with intravenous fluids a pyloromyotomy was performed at 21 days. A week later he was discharged well. During his 3 weeks in hospital, his urine was tested four times with 'Phenistix' and reported as negative. He was readmitted at 12 weeks of age after a routine urine chromatogram showed excessive phenylalanine excretion. His subsequent investigation and behaviour have confirmed a diagnosis of classical phenylketonuria.

It seems most likely that the vomiting in this infant produced what was in fact a low phenylalanine intake with a resulting serum phenylalanine level of moderate elevation-insufficient to produce measurable amounts of phenylpyruvic acid in the urine. Had the serum phenylalanine level been estimated, then this would almost certainly have been moderately elevated, but not as high as it would have been had he been on a normal milk intake. This patient also emphasizes the inadequacies of the ferric chloride test as a screening procedure.

Vomiting and feeding difficulties are early signs in phenylketonuria. Sometimes this may have a surgical basis; three infants had laparotomies performed when pyloric tumours were found. The incidence of hypertrophic pyloric stenosis seems high and may be related to the reported abnormalities in the metabolism of adrenaline, serotonin and related compounds (Cawte, 1957; Davidson \& Sandler, 1958).

\section{(ii) Phenylalanine transaminase defect}

Phenylketonuria with associated phenylalanine transaminase defects has been described by Anderson et al. (1966) and Auerbach, Di George \& Carpenter (1967). The children have high initial levels of serum phenylalanine, but their excretion of phenylpyruvic acid in the urine is small. They showed a marked improvement in phenylalanine tolerance after the first year of life. This led Auerbach and his colleagues to question the nature of the phenylalanine-tyrosine block. The children, in these reports, did not show signs of mental impairment on a normal diet.

\section{(iii) Associated with other defects of aminoacids}

Hyperphenylalaninaemia associated with other defects of aminoacid metabolism occur in the neonatal age group. Allen, Fleming \& Spirito (1967) reported that in 144 positive Guthrie tests found during a study of 104,785 babies, four had classical phenylketonuria and five had other metabolic abnormalities. The majority of the remaining infants had blood levels clearly related to birth weight and their serum levels had returned to normal when retested. Experience in this clinic suggests that this transient neonatal form is more common in heterozygotes for the phenylketonuric gene. 
TABLE 3. Phenylalanine tolerance tests in aypical phenylketonuric infants

\begin{tabular}{|c|c|c|c|c|c|c|}
\hline \multirow[t]{2}{*}{ Subject } & \multirow{2}{*}{$\begin{array}{c}\text { Age } \\
\text { (weeks) }\end{array}$} & \multirow{2}{*}{$\begin{array}{c}\text { Phenylalanine } \\
\text { tyrosine }\end{array}$} & \multicolumn{4}{|c|}{ Serum level $(\mathrm{mg} / 100 \mathrm{ml})$} \\
\hline & & & 0 & 1 & 2 & 4 \\
\hline C.L. & 6 & $\begin{array}{l}\text { P.A. } \\
\text { Tyr. }\end{array}$ & $\begin{array}{l}5 \cdot 8 \\
1 \cdot 2\end{array}$ & $\begin{array}{r}28 \cdot 1 \\
1 \cdot 1\end{array}$ & $\begin{array}{c}26 \cdot 1^{*} \\
1 \cdot 1\end{array}$ & $\begin{array}{r}28 \cdot 8 \\
1 \cdot 1\end{array}$ \\
\hline J.G. & 3 & $\begin{array}{l}\text { P.A. } \\
\text { Tyr. }\end{array}$ & $\begin{array}{l}9 \cdot 1 \\
1 \cdot 4\end{array}$ & $\begin{array}{r}22 \cdot 2 \\
1 \cdot 3\end{array}$ & $\begin{array}{c}23 \cdot 2^{*} \\
1 \cdot 0\end{array}$ & $\begin{array}{r}23.0 \\
0.9\end{array}$ \\
\hline D.G. & 4 & $\begin{array}{l}\text { P.A. } \\
\text { Tyr. }\end{array}$ & $\begin{array}{r}15.0 \\
1.9\end{array}$ & $\begin{array}{r}29 \cdot 2 \\
1.6\end{array}$ & $\begin{array}{c}35 \cdot 0^{*} \\
1 \cdot 3\end{array}$ & $\begin{array}{r}38 \cdot 4 \\
1 \cdot 1\end{array}$ \\
\hline
\end{tabular}

*Phenylpyruvic acid appeared in the urine from this point on.

\section{(iv) Atypical phenylketonuria}

The remaining infants of our series fall into the so called 'atypical' group.

These infants have elevated serum phenylalanine levels of 4-20 mg per $100 \mathrm{ml}$, but the levels are not as high as those reached in classical phenylketonuria (Hsia, O'Flynn \& Berman, 1968). On a normal diet, phenylpyruvic acid and orthohydroxyphenylacetic acid appear intermittently in the urine, but they nearly always appear with phenylalanine loading. Oral loading shows phenylalanine intolerance with a very poor rise in serum tyrosine. The prognosis for future intelligence in atypical cases is good (Hsia, O'Flynn \& Berman, 1968). The two major problems are the indications for dietary phenylalanine restriction and the pathogenesis of the disease.

Very low or no phenylalanine hydroxylase activity has been demonstrated in liver biopsy specimens from children with classical phenylketonuria (Justice, O'Flynn \& Hsia, 1967) while partial absence of the enzyme was found in atypical cases (Justice, O'Flynn \& Hsia, 1967; Woolf et al., 1968). The present techniques of ascertaining homozygotes and heterozygotes for the various forms of phenylketonuria are inadequate to determine whether atypical forms are due to multiple alleles at the phenylalanine hydroxylase locus or whether they represent the effects of one or more modifying genes (Yu \& O'Halloran, 1970; Woolf et al., 1968; Hsia, O'Flynn \& Berman, 1968).

\section{(v) Maternal phenylketonuria}

Serum aminoacid levels are higher on the foetal side than the maternal side of the placenta as phenylalanine actively crosses the placenta, as do the other aminoacids. The high serum phenylalanine levels of the mother with phenylketonuria will be reflected in the foetal serum levels and in the newly born infant immediately after birth. Guthrie testing may reveal this passively acquired abnormality even though it be a transient phenomenon (Denniston, 1963).

\section{Dietary management of classical phenylketonuria}

The management of phenylketonuria by a low dietary phenylalanine intake was first reported by Bickel, Garrard \& Hickman (1953). Since that time, dietary restrictions have been used widely by clinicians in all parts of the world with encouraging results (Medical Research Council, 1963; McBean \& Stephenson, 1968; Dobson et al., 1968; Brown \& Waisman, 1967). Bessman in 1966 questioned many aspects of phenylketonuria, including the efficacy of treatment and the ethics of mass screening surveys. The most important question raised by Bessman was whether the good results, reported by clinicians using dietary restrictions, are merely due to the inclusion of phenylketonuric children whose intellectual prognosis would have been good anyway, either with or without dietary restrictions. This implies that routine screening is merely revealing a pool of children with a benign biochemical abnormality. The number of phenylketonurics discovered who have a normal intelligence and who have no dietary restrictions is small.

However, there is considerable literature availatle supporting the efficacy of diet in preventing mental retardation or deterioration (Auerbach et al., 1967).

The problems of a low phenylalanine diet fall into two main groups:

(i) the maintenance of adequate nutrition and growth.

(ii) the management of the emotional difficulties of the patient and his family.

Phenylalanine is an essential aminoacid and its requirements vary with age and growth. Phenylalanine deficiency is characterized by failure of weight gain, rash in the nappy area, anorexia, lethargy, listlessness (Medical Research Council, 1963) and alopecia (Pitt, 1967). Phenylalanine requirements are higher in early infancy per unit weight than later life. Growth requirements increase rapidly over the first months of life (Snyderman et al., 1955; Kennedy et al., 1967), so that it is not possible to assess the phenylalanine requirement of infants by weight alone. The dangers of phenylalanine deficiency are very much greater in atypical phenylketonurics who show a greater tolerance to phenylalanine. Such infants need to be seen at very regular and frequent intervals.

Dietary deficiencies of folic acid (Royston \& Parry, 1962) and choline (Wilson \& Clayton, 1962) have been reported with low phenylalanine diets. 
Brown \& Waisman (1967) studied the siblings of probands with classical phenylketonuria and showed that retardation was not an incidental finding in phenylketonuria. In our clinic, there were sixty siblings, of affected children, with normal intelligence. None of them was found to be phenylketonuric. Six older phenylketonuric siblings were found, but all were known to te retarded before the diagnosis of phenylketonuria was made in the proband.

Recently Birch \& Tizard (1967) have called for a control trial of low phenylalanine diets in phenylketonuria. The evidence supporting the use of such a diet and the disastrous effects seen in the great majority of untreated phenylketonuric children make a control study ethically difficult. There is no method currently available by which one can assess whether the biochemical abnormality in an infant will be benign or whether it will result in retardation if not treated. The controversy is well reviewed by Woolf (1967).

This, of course, does not mean that the diet is easily managed by the parents or easily supervised in the clinic. It remains one of the more difficult and socially limiting of therapeutic diets.

Many of these problems can be avoided if the Medical Research Council's recommendations on dietary supplements are followed (Report to Medical Research Council, 1963). Complete vitamin supplements are prescribed as soon as a change in the milk diet has been effected in the newly diagnosed baby (Table 4). In the first 6 months of life, a 'low'

TABLE 4. Vitamin supplements supplied in phenylalanine-low diets (M.R.C. Report)

Aneurine hydrochloride
Riboflavine
Pyridoxine hydrochloride
Nicotinamide
Calcium pantothenate
Ascorbic acid
a-Tocopheryl acetate
Inositol
Biotin
Folic acid
Vitamin A
Vitamin D
Choline chloride
Cyanocobalamin

phenylalanine milk ('Lofenalac'-Mead Johnson) has been found to be more easily managed by the mother. This milk has been fortified with fat and carbohydrate, so presenting a balanced and a complete feeding. Its milk-like appearance and consistency help family acceptance of the change. 'Lofenalac', however, contains $80 \mathrm{mg}$ phenylalanine per $100 \mathrm{gm}$ of dry powdered milk and if the older infant and child is to receive most of his growth and maintenance protein from 'Lofenalac' there remains little of his daily phenylalanine allowance to be taken as other foods. From 6 to 9 months of age we commence to wean the infant slowly onto another milk hydrolysate, 'Cymogran' or 'Albumaid' which contain negligible amounts of phenylalanine. During this time, and until an adequate solid diet is attained, mineral supplements are given as listed in Table 5.

\begin{tabular}{l} 
TABLE 5. Mineral supplenents supplied in \\
phenylalanine-low diets (M.R.C. Report) \\
\hline Calcium lactate \\
Calcium chloride \\
Dipotassium hydrogen phosphate \\
Disodium hydrogen phosphate \\
Magnesium sulphate \\
Ferrous sulphate \\
Copper sulphate \\
Zinc chloride \\
Manganese sulphate \\
Potassium iodide \\
Potash alum \\
Cobalt sulphate \\
Sodium molybdate \\
Anhydrous sodium carbonate \\
Potassium carbonate \\
Calcium carbonate \\
\hline
\end{tabular}

'Albumaid' has the distinct advantage of being more easily incorporated into solid foods than 'Cymogran'.

\section{Dietary management of atypical phenylketonuria}

The management of atypical cases is equally controversial. While high grade phenylketonurics and atypical cases with normal intelligence undoubtedly exist in the population, mentally retarded persons with the atypical form of phenylketonuria have been described (Justice et al., 1967).

The mechanism of brain damage remains unknown, but seems to be related to a level of serum phenylalanine of $20 \mathrm{mg} / 100 \mathrm{ml}$ which remains a useful upper limit of safety (Hsia et al., 1968). Most workers prefer their treated children to have levels less than 10-12 mg/100 ml (Baumeister, 1967; McBean \& Stephenson, 1968).

The management of atypical cases varies markedly. Berry et al. (1967) treat their children when the serum phenylalanine level exceeds $15 \mathrm{mg} / 100 \mathrm{ml}$. Kennedy et al. (1967) treat all infants with initial fasting levels greater than $12 \mathrm{mg} / 100 \mathrm{ml}$ while Auerbach et al. (1967) only treat atypicals who excrete phenylpyruvic acid in excess of $15 \mathrm{mg} / 100 \mathrm{ml}$, or who maintain serum phenylalanine levels around $30 \mathrm{mg} / 100$ $\mathrm{ml}$. Many would not accept this last group as having the atypical form of the disease.

Atypical phenylketonurics in this clinic are treated with a low phenylalanine diet if their initial fasting serum phenylalanine level is over $15 \mathrm{mg} / 100 \mathrm{ml}$ or if, after an oral load, the 4-hr phenylalanine level is still 
over $15 \mathrm{mg} / 100 \mathrm{ml}$. Typical tolerance tests in three atypical infants are shown in Table 3. Two infants (C.L. and J.G.) had safe initial serum phenylalanine levels, but after an oral load of 1-phenylalanine 100 $\mathrm{mg} / \mathrm{kg}$ body weight, the level exceeded $20 \mathrm{mg} / 100 \mathrm{ml}$ at $1 \mathrm{hr}$ and after $4 \mathrm{hr}$ was still in excess of $20 \mathrm{mg} /$ $100 \mathrm{ml}$.

The average loading test in a neonate is equivalent to 2-3 times the phenylalanine load in a half strength cow's milk feeding of $100 \mathrm{ml}$ and so does not represent an unrealistic stress. There is no evidence that dietary restrictions are necessary for these atypical infants with serum levels less than $20 \mathrm{mg} / 100 \mathrm{ml}$, but whilst on such a diet, there will be no marked variation in serum phenylalanine levels through the day and certainly no transient peaks over $20 \mathrm{mg} / 100 \mathrm{ml}$. It is our policy to keep the fasting serum levels of phenylalanine over $5 \mathrm{mg} / 100 \mathrm{ml}$ in the atypical infants. The phenylalanine tolerance shown by atypical cases is much greater than in classical phenylketonuria. In early infancy, they tolerate $45 \mathrm{mg}$ phenylalanine per $\mathrm{kg}$ body weight per day or more. Classical phenylketonuric infants rarely tolerate an intake of $45 \mathrm{mg} / \mathrm{kg}$. This greater tolerance to phenylalanine continues through infancy and by 12-18 months allows a better variety in the foods allowed. We plan to abandon restrictions when the child reaches pre-schooling age, about 4-5 years.

\section{Duration of dietary restrictions}

The major problem in dietary management is when, and if, it is safe to stop treatment.

If phenylalanine interferes with myelinization (Crome, Tymms \& Woolf, 1962; Poser \& Van Bogaert, 1959; Crome, 1962) or with the constitution of cerebral lipid (Foote et al., 1965; Menkes, 1966; Menkes \& Aeberhard, 1969), then it would seem reasonable to stop the diet when brain growth is complete or myelinization is complete. Alternative mechanisms suggested as a cause of retardation are disordered 5-hydroxytryphophane metabolism (McKean, Schanberg \& Giarman, 1962) or interference with aminoacid transport (Neame, 1961). If these last two mechanisms are responsible, partly or wholly, there would be a case for some dietary modification to be carried out for life.

In a few cases of hyperactive retarded children, who were at the time untreated, we have noted an improvement in behaviour when the serum phenylalanine level was reduced to about $15 \mathrm{mg} / 100 \mathrm{ml}$. The modifications have produced a longer attention span and hence a greater learning ability, but have not otherwise altered the intellectual capacities of these children. These clinical impressions are supported by EEG studies which show that abnormal tracings may revert to normal with treatment and by the abnormal EEG patterns provoked during phenylalanine loading in affected children (Clayton et al., 1966).

Clinical impressions in other centres also suggest that children who are already brain-damaged to some degree may benefit from long-term dietary modifications if not strict dietary restrictions (Langdell, 1965). Such children in this clinic are kept on a largely vegetarian diet with protein supplied in the form of a low phenylalanine milk. There is no strict control of the quantity of low phenylalanine foods eaten by these children.

The foregoing principles may not hold for otherwise normal phenylketonuric children with normal development and intelligence. Some fifty to sixty children have had their diets terminated at 3-6 years and with rare exceptions no neurological, psychological, intellectual or behavioural changes have been noted (Berry \& Wright, 1967; Hackney et al., 1968). No subsequent reports have appeared which record any deterioration when diets are suspended in the otherwise normal child in the 3-6 years age group. Reports of increased irritability, restlessness, distractibility or autistic behaviour have generally occurred in children already showing minimal disabilities (Koch et al., 1964). It seems likely that a phenylketonuric child with evidence of brain damage may need dietary restrictions for a longer period than the otherwise normal phenylketonuric child.

\section{Maternal phenylketonuria}

Mass screening programmes and early dietary management will increase the number of homozygous phenylketonuric women in the community who are of normal intelligence and in the childbearing age.

References to the children of phenylketonuric mothers were made in the early literature, but it was not till the report of Mabry et al. (1966) that the full implications of maternal phenylketonuria on the offspring were appreciated. Recently the subject was reviewed by Yu \& O'Halloran (1970). They found that sixty-five of the sixty-eight reported children were retarded, twenty-eight were microcephalic, eight of their twelve children suffered from epilepsy.

Stevenson \& Huntley (1967) found a high incidence of congenital heart lesions, notably septal defects, and a high incidence of abortions and low birthweight infants in the affected families. Clearly, the maternal disease and the resulting high phenylalanine environment to which the foetus is exposed are much more serious than previously thought.

There is one reported case of a phenylketonuric woman being placed on a restricted diet during pregnancy (Allan \& Brown, 1968). The diet is said to have been given before pregnancy and then again in the last 5 months; no details are given about the diet in the early pregnancy. The infant resulting from 
this pregnancy appeared normal at 9 months of age.

The microcephaly, cardiac septal anomalies, frequent abortions and low birth-weight infants suggest that the factors responsible commence to have an effect early in pregnancy and continue to do so throughout intrauterine life.

Pregnancy is often difficult to diagnose in the early months, yet this is the stage at which the foetus may be most easily damaged by teratogens, in this case, phenylalanine or one of its metabolites.

A confident prognosis for the children of phenylketonuric mothers can only be given if the serum levels are controlled from the time of conception. As human vagaries preclude life-long dietary restrictions in these women, planned pregnancies and dietary restrictions during the fertile period and any subsequent pregnancy appear to be the only satisfactory method of management.

The supervision of these women and the meticulous control of all aspects of their diet will present the major challenge in the management of phenylketonuria in the next decade.

\section{References}

Allan, J.D. \& Brown, J.K. (1968) Maternal phenylketonuria and foetal brain damage in Some Recent Advances in some Inborn Errors of Metabolism. (Ed. by K. S. Holt and V. P. Coffey), Livingstone, London and Edinburgh.

Allen, R.J., Fleming, L. \& Spirito, R. (1967) Variations in Hyperphenylalaninaemia in Aminoacid Metabolism and Genetic Variation (Ed. by W. L. Nyhan), McGraw-Hill, New York.

Anderson, J.A., Fisch, R., Miller, E. \& Doeden, D. (1966) Atypical phenylketonuric heterozygote. Journal of Pediatrics, 68, 351.

Armstrong, M.D., Centerwall, W.R., Horner, F.A., Low, N.L. \& WEIL, W.B. JR (1961) The development of biochemical abnormalities in phenylketonuric children. Chemical Pathology of the Nervous System. (Ed. by J. Folch-Pi), P. 38, Pergamon Press, London.

Auerbach, V.H., Di George, A.M. \& Carpenter, G.G. (1967) Phenylalaninaemia in Aminoacid Metabolism and Genetic Variation. (Ed. by W. L. Nyhan), McGraw-Hill, New York.

Baumeister, A.A. (1967) The effects of dietary control on intelligence in phenylketonuria. American Journal of Mental Deficiency, 71, 840.

BerRy, H.K., SUTHERLAND, B.S., Umbarger, B. \& O'Grady, D. (1967) Treatment of phenylketonuria. American Journal of Diseases of Children, 113, 2.

BERRY, H.K. \& 'VRIGHT, S. (1967) Conference on treatment of phenylketonuria. Journal of Pediatrics, 70, 142.

Bessman, S.P. (1966) Legislation and advances in medical knowledge-acceleration or inhibition? Journal of Pediatrics, 69, 334

Bickel, H., Garrard, J.W. \& Hickman, E.M. (1953) Influence of phenylalanine intake on phenylketonuria. Lancet, ii, 812.

Birch, H.G. \& TIZARD, J. (1967) The dietary treatment of phenylketonuria: not proven? Developmental Medicine in Child Neurology, 9, 9.

Brown, E.S. \& WaISMAN, H.A. (1967) Intelligence of the unidentified phenylketonuric child. Pediatrics, 40, 247.
CAWTE, J.E. (1957) An attempt to determine reaction to adrenaline in phenylketonuria. Journal of Mental Deficiency Research, 1, 117.

Clayton, B., Moncrieff, A.A., Pampiglione, G. \& ShepHERD, J. (1966) Biochemical and EEG studies in phenylketonuric children during phenylanine tolerance tests. Archives of Disease in Childhood, 41, 267.

CROME, L. (1962) Association of phenylketonuria with leukodystrophy. Journal of Neurology, Neurosurgery and Psychiatry, 25, 149.

Crome, L., Tymms, V. \& Woolf, L.I. (1962) A chemical investigation of the defects of myelination in phenylketonurics. Journal of Neurology, Neurosurgery and Psychiatry, 25, 143.

Davidson, A.N. \& Sandler, M. (1958) Inhibition of 5hydroxytryptophan decarboxylase by phenylalanine metabolites. Nature, 181, 186.

Denniston, J.C. (1963) Children of mothers with phenylketonuria. Journal of Pediatrics, 63, 461.

Dobson, J., Косh, R., Williamson, M., Spector, R., FrankenburG, M., O'FlynN, M., WARNer, R. \& Hudson, F. (1968) Cognitive development and dietary therapy in phenylketonuric children. New England Journal of Medicine, 278, 1142.

Folling, A. (1934) Uber Ausscheidung von Phenylbrenztraubensauer in den Harn als Stoffwechselanomalia in Verbindung mit Imbezillitat. Journal of Physiological Chemistry, 227, 169.

Foote, J.L., Allen, R.J. \& Agranoff, B.W. (1965) Fatty acids in esters and cerebrosides of human brain in phenylketonuria. Journal of Lipid Research, 6, 518.

Fuller, R. (1967) Phenylketonuria: psychological and development evaluation. In Phenylketonuria and Allied Metabolic Disease. (Ed. by J. A. Anderson and K. F. Swaiman), p. 168. U.S. Department of Health, Education and Welfare, Children's Bureau, Washington.

GibBs, N.K. \& WoolF, L.I. (1959) Tests for phenylketonuria. Result of a one year programme for its detection in infancy and among mental defectives. British Medical Journal, 2, 532.

GUTHRIE, R. \& SUSI, A. (1963) A simple phenylalanine method for detecting phenylketonuria in large populations of newborn infants. Pediatrics, 32, 338.

HaCkNey, I.M., Handley, W.B., Davidson, W. \& Lindsao, L. (1968) Phenylketonuria : mental development, behaviour and termination of low phenylalanine diet. Journal of Pediatrics, 72, 646.

Hsia, D.Y-Y. (1967) Phenylketonuria 1967. Developmental Medicine and Child Neurology, 9, 531.

Hsia, D.Y-Y., O'FlynN, M.E. \& Berman, J.L. (1968) Atypical phenylketonuria with borderline or normal intelligence. American Journal of Diseases of Children, 116, 143.

Justice, P., O'Flynn, M.E. \& Hsia, D.Y-Y. (1967) Phenylalanine hydroxylase activity in hyperphenylalaninaemia. Lancet, i, 928.

Kennedy, J.L., Wertelecki, W., Gates, L., Sperry, B.P. \& CAss, V.M. (1967) The early treatment of phenylketonuria. American Journal of Diseases of Children, 113, 17.

Косн, R., Fischler, K., Schild, S. \& Ragsdale, N. (1964) Clinical aspects of phenylketonuria. Mental Retardation, $2,47$.

Langdell, J.I. (1965) Phenylketonuria. Archives of General Psychiatry, 12, 363.

Mabry, C.C., Denniston, J.C. \& Coldwell, J.G. (1966) Mental retardation in children of phenylketonuric mothers. New England Journal of Medicine, 275, 1331.

McBean, M.S. \& Stephenson, J.B.P. (1968) Treatment of classical phenylketonuria. Archives of Disease in Childhood, $43,1$. 
McKean, C.M., Schanberg, S.M. \& Giarman, N.J. (1962) A mechanism of the indole defect in experimental phenylketonuria. Science, 137, 604.

Medical Research Council Report (1963) Treatment of phenylketonuria. British Medical Journal, 1, 1691.

MENKES, J.H. (1966) Cerebral lipids in phenylketonuria. Paediatrics, 37, 967.

MenKes, J.H. \& Aeberhard, E. (1969) Maternal phenylketonuria-the composition of cerebral lipids in an affected offspring. Journal of Pediatrics, 74, 924.

Neame, K.D. (1961) Phenylalanine as inhibitor of transport of aminoacids in brain. Nature, 192, 173.

PITT, D. (1967) Phenylalanine maintenance in phenylketonuria. Australian Paediatric Journal, 3, 161.

Royston, N.J.W. \& PARRY, T.E. (1962) Megaloblastic anaemia complicating dietary treatment of phenylketonuria in infancy. Archives of Disease in Childhood. 37, 430.

Searle, B., Mijuskovic, M.B., Widelock, D. \& Davidow, B. (1967) A manual fluorimetric paper disc method for detecting phenylketonuria. Clinical Chemistry, 13, 621.

Snyderman, S.E., Pratt, E.L., Cheung, M.W., Norton, P. \& HolT, L.E. (1955) The phenylalanine requirement of the normal infant. Journal of Nutrition, 56, 253.

Stevenson, R.E. \& Huntley, C.C. (1967) Congenital malformations in offspring of phenylketonuric mothers. Pediatrics, 40, 33.

TURNeR, B. \& Brown, D.A. (1967) Detection of urinary abnormalities in a well baby population: results of a survey. Medical Journal of Australia, i, 560.
Wilson, K.M. \& CLAYTON, B.E. (1962) Importance of choline during growth with particular reference to synthetic diets in phenylketonuria. Archives of Disease in Childhood, 37, 656.

WooLF, L.I. (1967) Large scale screening for metabolic diseases in the newborn in Great Britain. In Phenylketonuria and Allied Metabolic Diseases (Ed. by J. A. Anderson and K. F. Swaiman), p. 50. U.S. Department of Health, Education and Welfare, Children's Bureau, Washington.

WooLf, L.I. (1967) The dietary treatment of phenylketonuria: not proven. Developmental Medicine in Child Neurology, 9, 244.

Woolf, L.I. (1968) Mass screening of the newborn for metabolic disease. Archives of Disease in Childhood, 43, 137.

WoOlf, L.I., Goodwin, B.L., Cranston, W.I., WADE, D.N. Woolf, F., Hudson, F.P. \& McBean, M.S. (1968) A third allele at the phenylalanine locus in mild phenylketonuria. (Hyperphenylalaninaemia.) Lancet, i, 114.

Woolf, L.I., Griffiths, R., Momcrieff, A., Contes, S. \& Dillistone, F. (1958) The dietary treatment of phenylketonuria. Archives of Disease in Childhood, 33, 31 .

Yu, J.S. \& O'Halloran, M.T. (1970) Children of phenylketonuric mothers. Lancet. i, 210.

Yu, J.S. \& O'Halloran, M.T. (1970) Atypical phenylketonuria in a family with a phenylketonuric mother. Pediatrics. (In press).

Yu, J.S., StuCKey, S.J. \& O'Halloran, M.T. (1970) Atypical phenylketonuria: an approach to diagnosis and management. Archives of Disease in Childhood. (In press).

\title{
Pneumatosis cystoides intestinalis
}

\author{
O. P. FitzGerald-Finch \\ M.B., B.S., M.R.C.S., L.R.C.P. \\ Southern General Hospital, Glasgow
}

\author{
J. K. Galloway \\ M.B., Ch.B.
}

\author{
M.B., Ch.B., D.Obst.R.C.O.G., F.F.R. \\ Victoria Infirmary, Glasgow \\ J. C. S. SMITH
}

Western Infirmary, Glasgow

X-Ray Department, Southern General Hospital, Glasgow, S.W.1.

\section{Summary}

A brief outline of the aetiology and pathogenesis of pneumatosis cystoides intestinalis is given followed by a review of four cases which have occurred in the Glasgow area recently. The radiological appearances of the condition are considered in detail.

Pneumatosis cystoides intestinalis (PCI) is a rare but well-documented condition in which intramural gas appears throughout the intestine. The radiological appearances may be characteristic and four cases which have occurred in the Glasgow area recently are presented to illustrate these appearances.

\section{Pathology}

The disease is characterized by gas-filled cysts lying submucosally and subserosally which can occur along the whole length of the bowel although the stomach and the duodenum are very rarely affected. The cysts are lined by a single layer of cuboidal or flattened endothelial cells and separated by hyaline tissue which is infiltrated with lymphocytes or histiocytes and occasional foreign-body giant-cells. The wall of the cyst retains its normal capillary blood supply. Analysis of the gas has varied in different reports from normal atmospheric air to a gas containing a high concentration of carbon dioxide $(15 \%)$.

\section{Site}

Although the condition was originally thought to be commoner in the small bowel (Koss, 1952) the disease is being more often reported in the large bowel but this may be due to increasing radiological awareness of the disease in this site (Colquhoun, 1965; Meikle, 1965; Dendy Moore, 1968). 